\title{
Genetic Diversity and Geographical Distribution of Phytoplasmas Associated with Potato Purple Top Disease in Mexico
}

\author{
M. E. Santos-Cervantes, CIIDIR-IPN, Unidad Sinaloa, Juan de Dios Bátiz Paredes No. 250, Guasave, Sinaloa, \\ México CP 81101, and Programa Regional del Noroeste para el Doctorado en Biotecnología, FCQB-UAS, Culiacán, \\ Sinaloa, México; J. A. Chávez-Medina, CIIDIR-IPN, Unidad Sinaloa, Juan de Dios Bátiz Paredes No. 250, Gua- \\ save, Sinaloa, México CP 81101; J. Acosta-Pardini, Programa de Ingeniero Biotecnólogo. Instituto Tecnológico de \\ Sonora, Cd. Obregón, Sonora, México; and G. L. Flores-Zamora, J. Méndez-Lozano, and N. E. Leyva-López, \\ CIIDIR-IPN, Unidad Sinaloa, Juan de Dios Bátiz Paredes No. 250, Guasave, Sinaloa, México CP 81101
}

\begin{abstract}
Santos-Cervantes, M. E., Chávez-Medina, J. A., Acosta-Pardini, J., Flores-Zamora, G. L., Méndez-Lozano, J., and Leyva-López, N. E. 2010. Genetic diversity and geographical distribution of phytoplasmas associated with potato purple top disease in Mexico. Plant Dis. 94:388-395.

Potato purple top (PPT) disease has caused severe economic losses in some potato (Solanum tuberosum) growing areas of Mexico. Two distinct phytoplasma strains belonging to the aster yellows and peanut witches'-broom groups (16SrI and 16SrII groups) have been associated with PPT disease in several regions of Mexico. However, there has been no previous large-scale survey in the main potato growing areas in Mexico to analyze the diversity and geographical distribution of phytoplasmas. Potato samples were collected between 2003 and 2006 and were analyzed by nested polymerase chain reaction assays. On the basis of results from nucleotide sequence comparisons and virtual restriction fragment length polymorphism analysis of $16 \mathrm{~S}$ rDNA, four different phytoplasma groups were detected in potato growing areas in Mexico. The aster yellows group (16SrI) 'Candidatus Phytoplasma asteris' was distributed in all potato growing areas, whereas peanut witches'-broom group (16SrII) 'Candidatus Phytoplasma aurantifolia' was detected in Guanajuato and Sinaloa, X-disease group (16SrIII) was detected in Coahuila and Guanajuato, and the Mexican periwinkle virescence (16SrXIII) was only detected in Sinaloa. Phytoplasmas from X-disease and Mexican periwinkle virescence groups were detected in potato samples for the first time in Mexico.
\end{abstract}

The potato (Solanum tuberosum L.) is one of the most important crops cultivated for local consumption and industry in Mexico. The national production in 2008 was 1.67 million metric tons with a value of US\$603 million (43). In recent years, phytoplasmas have been found associated with potato purple top (PPT) disease in Mexico (29). This disease is considered an important limiting factor in the potato production in this country. In 2003 and 2004, the incidence of PPT disease caused significant economic losses in the Mexican state of Coahuila. Currently, PPT disease has been spread in all major potato growing areas in Mexico. Symptoms of the disease are purple discoloration (purple

Corresponding author: N. E. Leyva-López

E-mail: neleyval@ipn.mx

Accepted for publication 3 November 2009.

doi:10.1094/PDIS-94-4-0388

This article is in the public domain and not copyrightable. It may be freely reprinted with customary crediting of the source. The American Phytopathological Society, 2010. top) or yellowing of upper leaflets, apical leafroll, axillary buds, and the formation of aerial tubers. Storage tubers from affected plants do not sprout, or the sprouting is of extremely weak stems deficient in chlorophyll giving the appearance of white threads (34). However, we have observed that some infected tubers showed normal sprouting and could be an important spreading factor of phytoplasma diseases in potato growing areas. Moreover, the crops are unmarketable since the tubers show a normal appearance, but a dark color is observed when they are processed, causing a considerable economic loss in the potato industry. The symptoms of PPT disease resemble those of zebra chip, a disorder of potato recently found to be associated with 'Candidatus Liberibacter solanacearum' in New Zealand and the United States $(1,30)$.

Phytoplasma diseases of potato have been reported in several countries around the world including Mexico $(29,34)$, the United States (3,22-25,40,44,48), Canada (20,21), Bolivia (18), Australia (12), Korea (19), Russia (7), and New Zealand (32). At least eight distinct phytoplasma strains have been associated with PPT disease around the world. The most common phytoplasma groups causing the disease are aster yellows (16SrI-A and 16SrI-B), peanut witches'-broom (16SrII), clover proliferation (16SrVI-A), and stolbur (16SrXII-A). Recently, 'Candidatus Phytoplasma americanum' (16SrXVIII-A and 16SrXVIII-B) and $\mathrm{X}$-disease group (16SrIII-M) have been associated with PPT disease in the United States $(23,24)$. Leyva-López et al. (29) characterized two phytoplasma strains belonging to the aster yellows and peanut witches'-broom groups (16SrI and 16SrII groups) associated with PPT disease in samples collected in several regions of Mexico. However, there has been no previous large-scale survey of the main potato growing areas in Mexico to analyze the genetic diversity and geographical distribution of phytoplasmas. This paper reports the results of a 4-year survey on the genetic diversity and geographical distribution of phytoplasma groups associated with PPT disease in Mexico. In addition, two phytoplasma strains associated with PPT disease not previously reported in Mexico were molecularly characterized by virtual restriction fragment length polymorphism (RFLP) profiles and 16S rDNA sequence analysis.

\section{MATERIALS AND METHODS}

Plant samples. Foliage from 575 potato plants (173 asymptomatic and 402 symptomatic) and 2,419 asymptomatic potato tubers (potato seed and freshly harvested tubers) were collected between 2003 and 2006 in the main potato growing areas in Mexico including Sinaloa (SIN), Sonora (SON), Chihuahua (CHI), Guanajuato (GTO), Coahuila (COAH), Jalisco (JAL), and Baja California (BC) (Fig. 1 and Table $1)$. $\mathrm{BC}$ is not one of the main potato producers, but it is important as a seed potato producer. At least three fields from each potato growing area and five potato plants per field were sampled.

DNA extraction. Total nucleic acid was extracted as described elsewhere (49), except that $200 \mathrm{mg}$ of fresh tissue was 
transferred to a 1.5-ml tube and ground in $800 \mu \mathrm{l}$ of preheated CTAB extraction buffer $\left(60^{\circ} \mathrm{C}\right)(3 \%$ [foliage] and $4 \%$ [tubers] CTAB, $1.4 \mathrm{M} \mathrm{NaCl}, 20 \mathrm{mM}$ EDTA, 100 $\mathrm{mM}$ Tris- $\mathrm{HCl}, \mathrm{pH} 8.0,0.2 \%$ mercaptoethanol), followed by incubation at $60^{\circ} \mathrm{C}$ for 30 min. Samples were extracted with chloroform-isoamylalcohol (24:1). The aqueous DNA layer was precipitated with $600 \mu \mathrm{l}$ of cold isopropanol. DNA pellets were washed with $70 \%$ ethanol, dried, and suspended in 20 to $80 \mu \mathrm{l}$ of sterile twice-distilled water.

Detection of phytoplasmas in potato samples. Two "universal" phytoplasma nested primers were used for the detection of phytoplasma. R16mF2/R16mR1 and $\mathrm{R} 16 \mathrm{~F} 2 \mathrm{n} / \mathrm{R} 16 \mathrm{R} 2$ primers were used to amplify a portion of the $16 \mathrm{~S}$ rDNA (9). Polymerase chain reaction (PCR) amplifications were conducted in an automated thermocycler (model Icycler, BioRad, USA), as previously described (39). PCR products were analyzed by electrophoresis in a $1 \%$ agarose gel and visualized by staining with ethidium bromide and UV illumination. DNA samples extracted from potato tissues (foliage and tubers) were used as template for PCR. DNA extracted from asymptomatic foliage and tubers and sterile water were used as negative controls. Total genomic DNA from a previ- ously characterized phytoplasma infecting Opuntia spp., belonging to the peanut witches'-broom group (16SrII, GenBank accession number AF200718), was used as positive control (28).
Cloning of PCR products and sequencing of DNA. To verify nested PCR fragments amplified by universal phytoplasma primer pairs $\mathrm{R} 16 \mathrm{mF} 2 / \mathrm{R} 16 \mathrm{mR} 1$ and $\mathrm{R} 16 \mathrm{~F} 2 \mathrm{n} / \mathrm{R} 16 \mathrm{R} 2$ (9), a representative num-

Table 1. Phytoplasma detections in potato tubers and foliage of different geographic areas in Mexico using nested polymerase chain reaction (PCR) with primers pairs R16mF2-R16mR1/R16F2n-R16R2

\begin{tabular}{|c|c|c|c|c|}
\hline \multirow[b]{2}{*}{ Location } & \multirow[b]{2}{*}{ Year } & \multicolumn{2}{|c|}{$\begin{array}{l}\text { Plant tissue positive samples/ } \\
\text { total samples }\left(\%^{a}\right)\end{array}$} & \multirow{2}{*}{$\begin{array}{l}\text { Classification } 16 \mathrm{Sr} \\
\text { group and subgroup }\end{array}$} \\
\hline & & Tuber & Foliage & \\
\hline Sinaloa & 2003 & $4 / 200(2)$ & $0 / 68(0)$ & $\mathrm{ni}$ \\
\hline Sinaloa & 2004 & $5 / 95(5)$ & $0 / 60(0)$ & $\mathrm{ni}$ \\
\hline Sinaloa & 2005 & $50 / 569(9)$ & $5 / 6(83)$ & 16SrI-S \\
\hline Sinaloa & 2006 & $45 / 100(45)$ & $14 / 26(54)$ & 16SrI-S, 16SrII-C, 16SrXIII-D \\
\hline Coahuila & 2003 & 7/97 (7) & $13 / 134(10)$ & 16SrI-S, 16SrI-T \\
\hline Coahuila & 2004 & $9 / 40(23)$ & $1 / 11(9)$ & 16SrI-S, 16SrI-T, 16SrIII-S \\
\hline Coahuila & 2005 & $16 / 55(29)$ & $24 / 25(96)$ & 16SrI-S, 16SrI-T, 16SrIII-S \\
\hline Coahuila & 2006 & 10/73 (14) & $16 / 55(29)$ & 16SrI-S, 16SrI-T, 16SrIII-S \\
\hline Guanajuato & 2003 & $6 / 499(1)$ & $1 / 34(3)$ & 16SrI-S, 16SrII-M \\
\hline Guanajuato & 2004 & 2/246 (1) & $9 / 152(6)$ & 16SrI-S, 16SrI-T, 16SrIII-S \\
\hline Guanajuato & 2005 & na & $4 / 4(100)$ & 16SrI-S, 16SrI-T, 16SrIII-S \\
\hline Sonora & 2004 & $13 / 39(33)$ & na & $16 \mathrm{SrI}-\mathrm{V}$ \\
\hline Sonora & 2005 & $1 / 3(33)$ & na & $16 \mathrm{SrI}-\mathrm{V}$ \\
\hline Chihuahua & 2004 & $8 / 100(8)$ & na & $\mathrm{ni}$ \\
\hline Chihuahua & 2005 & 0/200 (0) & na & $\mathrm{ni}$ \\
\hline Baja California & 2004 & $8 / 60(13)$ & na & 16SrI-S \\
\hline Jalisco & 2004 & $0 / 15(0)$ & na & $\mathrm{ni}$ \\
\hline Jalisco & 2006 & $4 / 28$ (14) & na & 16SrI-S, 16SrI-U \\
\hline Total & & $188 / 2419$ & $87 / 575$ & \\
\hline
\end{tabular}

${ }^{a}$ Percentage of positive samples over total plants. ni: not identified, na: not available.

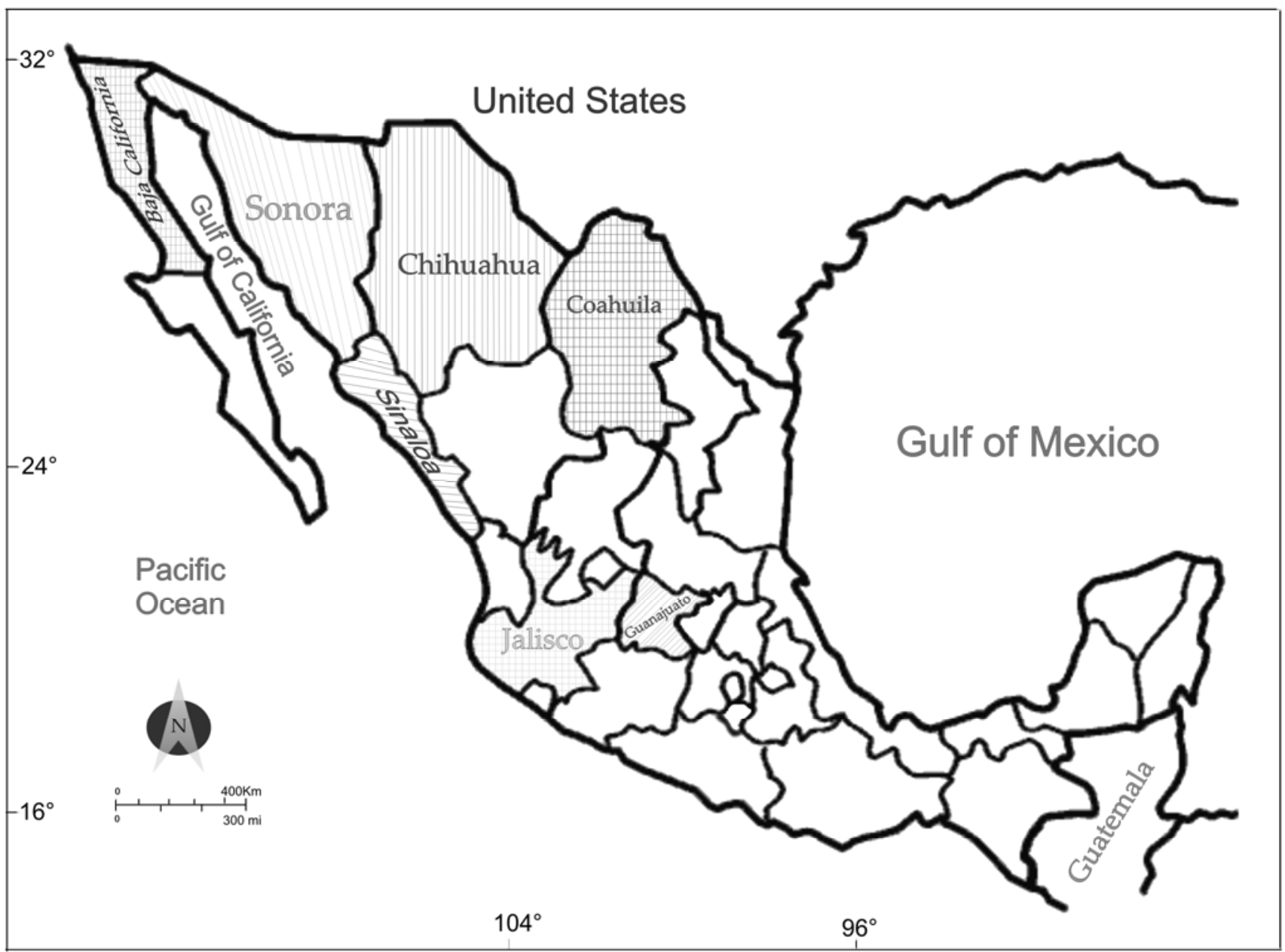

Fig. 1. Map of Mexico showing different geographic areas in which potato samples were collected. 
ber of PPT phytoplasma isolates from different potato growing areas in Mexico and from different years of study were selected after RFLP analysis, purified with Genclean III kit (Gibco-BRL), and ligated onto the pGEM-T vector (Promega Corporation). The ligation mixture was used to transform Escherichia coli DH5 $\alpha$ (Promega). Plasmid DNA from cultures of recombinant colonies was purified using QIAprep Spin Miniprep Kit (QIAGEN $\mathrm{GmbH})$. Both strands of two different clones of each phytoplasma isolate were sequenced completely twice in an $\mathrm{ABI}$ PRISM 377 sequencer using the Dye cycle Sequencing kit (Applied Biosystems). The sequences of $16 \mathrm{~S}$ rDNA from PPT phytoplasmas were deposited in GenBank with the accession numbers given in Table 2 and Figure 2.

DNA sequence analysis and in silico enzyme digestions. The nucleotide sequence data were edited using the EditSeq program of the sequence analysis software suite Lasergene (DNASTAR Inc.). BLAST was used to compare our sequences against DNA sequences available in the National Center for Biotechnology Information (NCBI). Virtual RFLP patterns were performed from the partial sequences of the $16 \mathrm{~S}$ rDNA gene using the virtual gel plotting program pDRAW32 (AcaClone). Each aligned DNA fragment was digested in silico with 17 distinct restriction enzymes (AluI, BamHI, BfaI, BstUI, DraI, EcoRI, HaeIII, HhaI, HinfI, HpaI, HpaII, KpnI,
Sau3AI, MseI, RsaI, SspI, and TaqI) that have been routinely used for phytoplasma 16S rRNA gene RFLP analysis (26). The virtual RFLP patterns were compared and a similarity coefficient $(\mathrm{F})$ was calculated for each pair of phytoplasma strains using a Perl program developed by Wei et al. (47).

For validation of the new $16 \mathrm{Sr}(-\mathrm{I})$, -II, -III, and -XIII subgroups delineated on the basis of virtual RFLP analysis, actual gel-based PCR-RFLP analysis was performed on 16S rRNA gene F2nR2 fragments amplified from representative strains of each new -I, -II, -III, and -XIII subgroup. DNA from pepper and tomato plants infected with PeLL and ToLL phytoplasmas (16SrI-S and 16SrI-T subgroups, respectively) were used as reference strains (39) in virtual and actual RFLP analysis, and the sequences from FBP (16SrII-C), MW1 (16SrIII-F), and MPV (16SrXIII-A) were used as reference strains (28) in virtual RFLP analysis, since those phytoplasma strains had the highest identity with the new subgroups identified in this study. F2nR2 nested PCR amplicons generated with the primer pairs R16mF2/R16mR1 and $\mathrm{R} 16 \mathrm{~F} 2 \mathrm{n} / \mathrm{R} 16 \mathrm{R} 2$ were digested with the respective restriction enzymes (AluI, BstUI, HinfI, HpaII, MseI, RsaI) according to the manufacturer's instructions (New England Biolabs). The digestion products were fractionated by electrophoresis using $3.0 \%$ agarose gels and stained in ethidium bromide.
Phylogenetic analysis. Nearly complete 16S rDNA sequences from PPT phytoplasmas along with 19 ' $\mathrm{Ca}$. Phytoplasma' species, other phytoplasmas representing distinct phytoplasma groups or subgroups, and Acholeplasma palmae were aligned using the Clustal W program of the sequence analysis software suite Lasergene (DNASTAR). The phylogenetic tree was generated using the Clustal W program through the neighbor-joining method. $A$. palmae was employed as the out-group to root the tree. Bootstrapping was performed 1,000 times for estimation of stability and support for the branches.

\section{RESULTS}

Detection of phytoplasmas from potato tubers and foliage samples. Phytoplasmas were detected by nested PCR with universal primer pairs $\mathrm{R} 16 \mathrm{~F} 2 \mathrm{n} / \mathrm{R} 16 \mathrm{R} 2$ and $\mathrm{R} 16 \mathrm{mF} 2 / \mathrm{R} 16 \mathrm{mR} 1$ in all main potato growing areas in Mexico in samples collected between 2003 and 2006. Eighty-seven out of 575 samples and 188 out of 2,419 samples from foliage and asymptomatic potato tubers, respectively, were infected with phytoplasmas (Table 1). Only two out of 173 asymptomatic potato plants gave positive PCR results. Not all the freshly harvested tubers from a phytoplasma infected potato plant were PCR positive to phytoplasmas.

Nucleotide sequence analysis and in silico enzyme digestions. The F2nR2 amplified fragments (approximately 1.25

Table 2. Similarity coefficients derived from analysis of virtual restriction fragment length polymorphism (RFLP) patterns of 16S rRNA genes from phytoplasma strains in the aster yellows (16SrI), peanut witches'-broom (16SrII), X-disease (16SrIII), and Mexican periwinkle virescence (16SrXIII) groups and 17 potato-infecting phytoplasma strains ${ }^{\mathrm{a}}$

\begin{tabular}{|c|c|c|}
\hline Serial Strain & $\begin{array}{l}\text { Subgroup representative/ } \\
\text { (GenBank accession) }\end{array}$ & \begin{tabular}{|llllllllllllllllllllllllllllllllllllllllllllll}
1 & 2 & 3 & 4 & 5 & 6 & 7 & 8 & 9 & 10 & 11 & 12 & 13 & 14 & 15 & 16 & 17 & 18 & 19 & 20 & 21 & 22 & 23 & 24 & 25 & 26 & 27 & 28 & 29 & 30 & 31 & 32 & 33 & 34 & 35 & 36 & 37 & 38 & 39 & 40 & 41 & 42 & 43 \\
\end{tabular} \\
\hline $1 \mathrm{AY}-\mathrm{WB}$ & $(16 S r \mid-A) A Y 389828$ & 1.00 \\
\hline $2 \mathrm{AY}$ & (16Srl-B) AY180943 & 0.921 .00 \\
\hline $3 \mathrm{CPh}$ & (16SrI-C) AF222066 & 0.910 .931 .00 \\
\hline 4 AYS-O & (16SrI-0) AF268405 & 0.860 .790 .801 .00 \\
\hline 5 AY-IP & (16SrI-P) AF503568 & 0.920 .940 .940 .801 .00 \\
\hline 6 CherLL & $(16 \mathrm{Sr}-\mathrm{Q})$ AY034089 & 0.840 .920 .840 .800 .861 .00 \\
\hline 7 StarwbPf & (16SrI-R) AY102275 & 0.910 .930 .930 .800 .930 .891 .00 \\
\hline 8 PeLL & (16SrI-S) DQ092321 & 0.880 .960 .880 .850 .900 .900 .901 .00 \\
\hline 9 ToLL & (16Srl-T) DQ375238 & 0.850 .860 .850 .820 .870 .870 .870 .971 .00 \\
\hline 10 PPT-BC1 & (16Srl-S) FJ914648 & 0.880 .960 .880 .850 .900 .900 .901 .000 .971 .00 \\
\hline 11 PPT-BC8 & (16Srl-S) FJ914653 & 0.880 .960 .880 .850 .900 .900 .901 .000 .971 .001 .00 \\
\hline 12 PPT-BC15 & (16Srl-S) FJ914638 & 0.880 .960 .880 .850 .900 .900 .901 .000 .971 .001 .001 .00 \\
\hline 13 PPT-GTO5 & (16Srl-S) FJ914649 & 0.880 .890 .880 .850 .900 .900 .901 .000 .971 .001 .001 .001 .00 \\
\hline 14 PPT-JAL2 & (16Srl-S) FJ914640 & 0.880 .890 .880 .850 .900 .900 .901 .000 .971 .001 .001 .001 .001 .00 \\
\hline 15 PPT-SIN6 & (16Srl-S) FJ914652 & 0.880 .890 .880 .850 .900 .900 .901 .000 .971 .001 .001 .001 .001 .001 .00 \\
\hline 16 PPT-SIN15 & (16Srl-S) FJ914641 & $\begin{array}{ll}0.870 .940 .870 .830 .880 .880 .880 .980 .950 .980 .9800 .980 .980 .980 .981 .00\end{array}$ \\
\hline 17 PPT-COAH10 & (16SrI-S) FJ914654 & 0.870 .950 .870 .840 .890 .890 .880 .990 .960 .990 .990 .990 .990 .990 .990 .971 .00 \\
\hline 18 PPT-COAH19 & (16Srl-T) FJ914639 & $0.850 .860 .850 .820 .870 .870 .870 .97 \quad 1.000 .970 .970 .970 .970 .970 .970 .950 .961 .00$ \\
\hline 19 PPT-JAL6 & (16Srl-U) FJ914650 & 0.870 .930 .870 .840 .870 .870 .880 .970 .940 .970 .970 .970 .970 .970 .970 .950 .960 .941 .00 \\
\hline 20 PPT-SON18 & (16Srl-V) FJ914642 & 0.850 .930 .850 .820 .870 .870 .870 .970 .940 .970 .970 .970 .970 .970 .970 .950 .960 .940 .941 .00 \\
\hline 21 PnWB & $(16$ S rIl $\mid-A)$ L33765 & 0.410 .480 .450 .290 .430 .390 .400 .410 .360 .410 .410 .410 .360 .340 .360 .410 .400 .360 .420 .421 .00 \\
\hline 22 'Ca. P. aurantifolia' & (16Sill-B) U15442 & 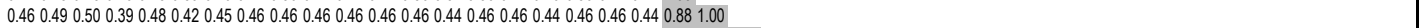 \\
\hline $23 \mathrm{FBP}$ & $(16$ Sill-C) $) 83432$ & 0.500 .500 .530 .430 .510 .460 .490 .500 .500 .500 .500 .500 .500 .500 .500 .500 .480 .500 .500 .480 .940 .941 .00 \\
\hline 24 'Ca. P. australasia' & (16Srll-D) Y10097 & 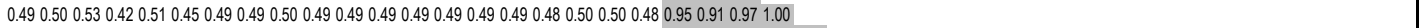 \\
\hline 25 CaWB-YN01 & (16SrII-L) EU099546 & 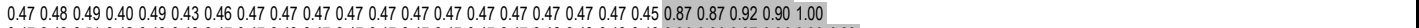 \\
\hline 26 PPT-GTO29 & (16SrII-M) FJ914643 & 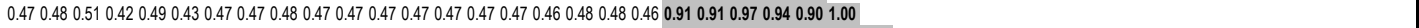 \\
\hline 27 PPT-GTO30 & (16Srll-M) FJ914644 & 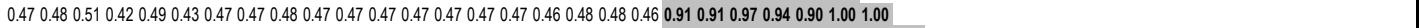 \\
\hline 28 PPT-SINTV & (16SrII-C) FJ914651 & 0.500 .500 .530 .430 .510 .460 .490 .500 .500 .500 .500 .500 .500 .500 .500 .500 .480 .500 .500 .480 .940 .941 .000 .970 .920 .970 .971 .00 \\
\hline $29 \mathrm{WX}$ & (16SrIII-A) L04682 & 0.550 .500 .550 .460 .530 .450 .530 .490 .510 .490 .490 .490 .490 .490 .490 .470 .480 .510 .500 .480 .590 .650 .630 .620 .570 .620 .620 .631 .00 \\
\hline 30 CYE & (16SrIII-B) AF175304 & 0.590 .540 .590 .500 .570 .490 .570 .530 .550 .530 .530 .530 .530 .530 .530 .530 .510 .550 .530 .510 .570 .630 .670 .660 .610 .660 .660 .670 .901 .00 \\
\hline $31 \mathrm{SP1}$ & (16SrIII-E) AF190228 & 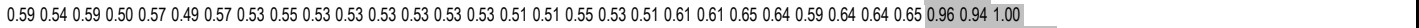 \\
\hline 32 MW1 & (16SrIII-F) AF510724 & 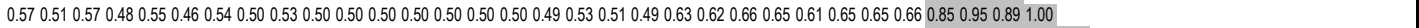 \\
\hline 33 WWB & (16SrIll-G) AF190226 & 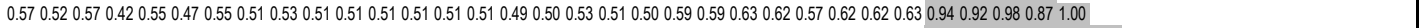 \\
\hline 34 PoiBl & (16Srlll-H) AF19022 & 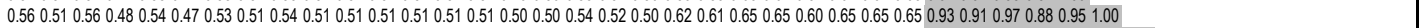 \\
\hline 35 VGYIII & (16SrIIIII) AF060875 & 0.590 .460 .590 .500 .570 .490 .570 .530 .550 .530 .530 .530 .530 .530 .530 .470 .510 .550 .530 .510 .480 .530 .590 .580 .530 .580 .580 .590 .900 .940 .940 .820 .920 .971 .00 \\
\hline 36 ChWBIII & (16SrIll-J) AF147706 & 0.570 .510 .570 .480 .550 .460 .540 .500 .530 .500 .500 .500 .500 .500 .500 .500 .490 .530 .510 .490 .630 .620 .660 .650 .610 .650 .650 .660 .870 .970 .910 .980 .890 .900 .851 .00 \\
\hline 37 DanVir & (16SrIII-P) AF370119 & 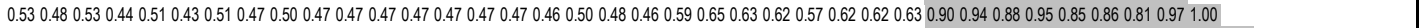 \\
\hline 38 BRWB7 & (16SrIll-Q) AF302841 & 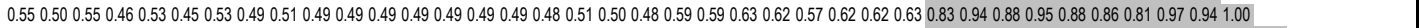 \\
\hline 39 PPT-COAHP & (16SrIII-U) FJ914645 & 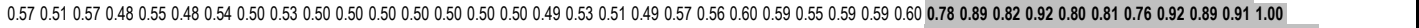 \\
\hline 40 PPT-GTOP & (16Srlll-U) FJ914646 & 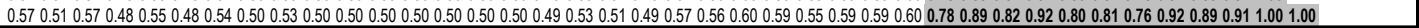 \\
\hline $41 \mathrm{MPV}$ & (16SrXIII-A) AF248960 & 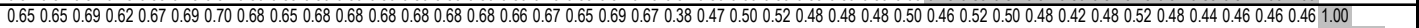 \\
\hline 42 ChTYXIII-4 & (16SrXIII-C) DQ444264 & 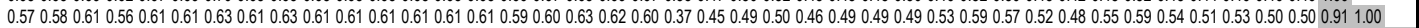 \\
\hline 43 PPT-SINPV & (16SrXIII-D) FJ914647 & 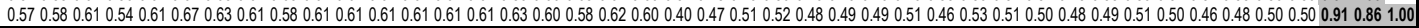 \\
\hline
\end{tabular}

${ }^{a}$ New subgroups are shown in bold. For each strain of a new subgroup, the similarity coefficients are equal to or lower than 0.97 with all strains in previously delineated subgroups. 
kb) were analyzed by actual RFLP (data not shown) to select representative amplicons from each year and potato growing areas in Mexico. At least 20 potato phyto- plasma isolates were selected and analyzed by actual RFLP from each amplicon cloned. The amplicons from each year and potato growing area in Mexico that yielded the same RFLP profile and those potato phytoplasmas isolated that presented $100 \%$ identity were discarded from this study; 17 representative isolates were selected both

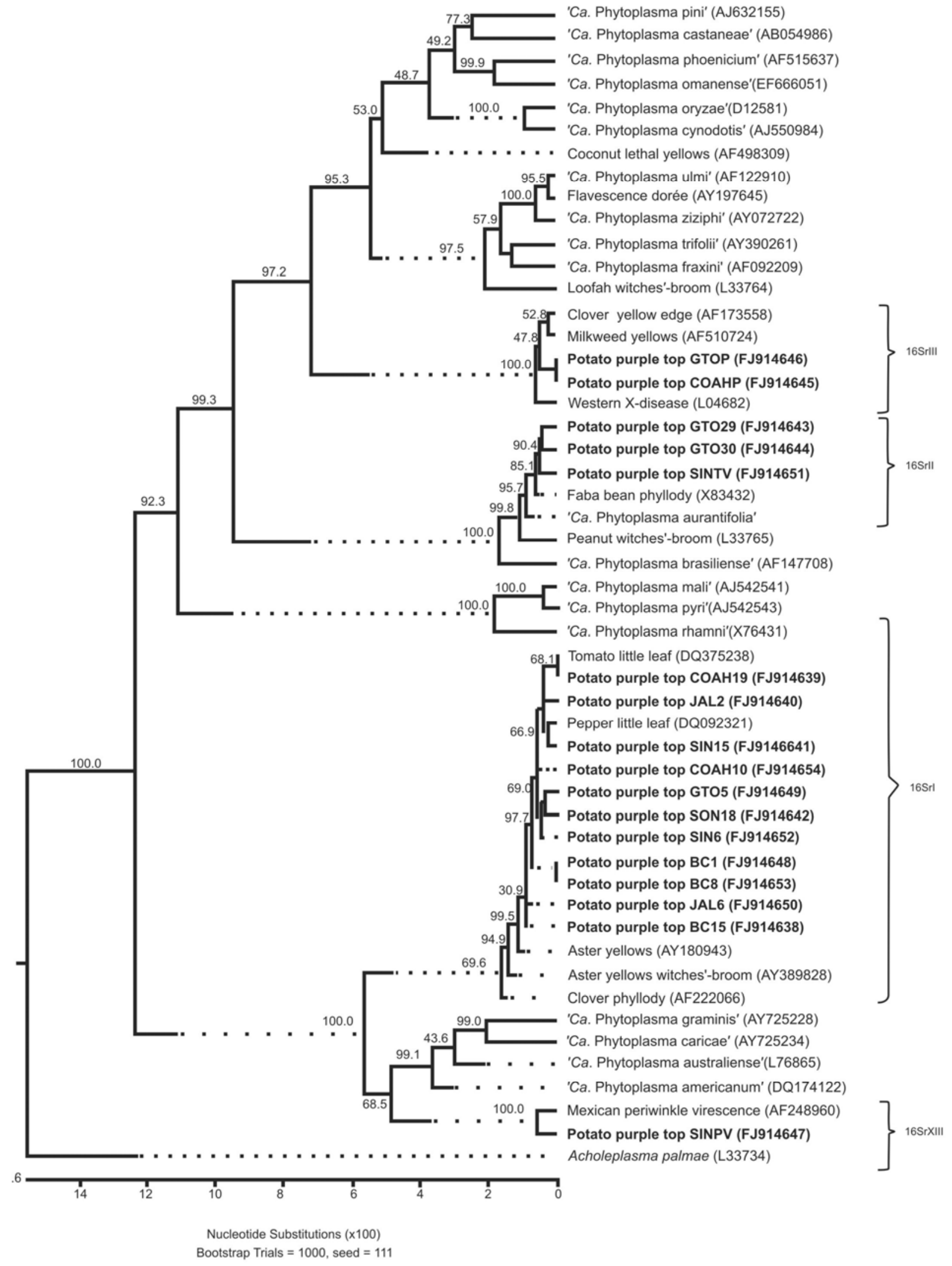

Fig. 2. Phylogenetic distance tree constructed by the Clustal W alignment method (DNASTAR) comparing 16S rDNA gene sequences from potato purple top phytoplasmas with sequences of 19 'Candidatus Phytoplasma' species and 14 other key phytoplasma groups and subgroups. Acholeplasma palmae was used as the outgroup for the phylogenetic tree reconstruction. Bootstrap (confidence) values are shown on the branches. GenBank accession numbers for sequences are given in parentheses. Phytoplasma strains from this study are in bold. 
from different potato growing areas in Mexico and from different year of study. These 16S rDNA sequences were compared with those in the NCBI/GenBank database. Eleven PPT phytoplasma isolates had maximum identity (99\%) with several strains of the aster yellows group (16SrI) ' $C a$. P. asteris'; three PPT phytoplasma isolates had maximum identity $(99 \%)$ with several strains of the peanut witches'broom group (16SrII) ' $C a$. P. aurantifolia'; two PPT phytoplasma isolates had maximum identity $(99 \%)$ with strains of the Xdisease group (16SrIII); and one PPT phytoplasma isolate had maximum identity (99\%) with strains of the Mexican periwinkle virescence group (16SrXIII). These results revealed the occurrence of four different phytoplasma groups infecting potato crops in Mexico (groups 16SrI, 16SrII, 16SrIII, and 16SrXIII). ' $\mathrm{Ca}$. P. asteris' was distributed in all potato growing areas, whereas peanut witches'-broom group (16SrII) ' $C a$. P. aurantifolia' was detected in GTO and SIN, the X-disease group (16SrIII) was detected in COAH and GTO, and the Mexican periwinkle virescence group (16SrXIII) was only detected in SIN (Table 1).

Phytoplasma isolates detected in potato samples classified as strains of ' $\mathrm{Ca}$. P. asteris' were designated as PPT-BC1, PPTBC8, PPT-BC15, PPT-COAH10, PPTCOAH19, PPT-GTO5, PPT-JAL2, PPTJAL6, PPT-SIN6, PPT-SIN15, and PPTSON18 (Table 2). Phytoplasma isolates detected in potato samples classified as strains of ' $\mathrm{Ca}$. P. aurantifolia' were designated as PPT-GTO29, PPT-GTO30, and PPT-SINTV (Table 2), phytoplasma isolates detected in potato samples classified as strains of the $\mathrm{X}$-disease group (16SrIII) were designated as PPT-COAHP and PPTGTOP (Table 2), and one phytoplasma isolate detected in potato samples classified as a strain of the Mexican periwinkle virescence group (16SrXIII) was designated as PPT-SINPV (Table 2).

Virtual RFLP analysis of 16S rRNA sequences was used to assign PPT strains to groups and subgroups $(46,47)$. Results from pairwise comparison of virtual $16 \mathrm{~S}$ rRNA gene F2nR2 RFLP patterns revealed that eight of the 11 16SrI PPT phytoplasma strains identified in potato samples had a pattern type identical to PeLL phytoplasma, while one 16SrI PPT phytoplasma strain (PPT-COAH19) had a pattern type identical to ToLL phytoplasma; therefore, the eight phytoplasma strains are considered to be new members of subgroup 16SrI-S, and the PPT-COAH19 phytoplasma strain is considered to be a new member of subgroup $16 \mathrm{SrI}-\mathrm{T}$. The remaining two strains (PPT-JAL6 and PPTSON18) showed two different virtual RFLP patterns that differed at least one band with each other and from those of the previously described subgroups, and their similarity coefficients were equal to or less than 0.97 with each of the other known subgroups (Fig. 3 and Table 2); therefore, PPT-JAL6 and PPT-SON18 phytoplasma strains were designated as new subgroups, $\mathrm{U}$ and $\mathrm{V}$ (16SrI-U and $16 \mathrm{SrI}-\mathrm{V}$, respectively), following criteria reported by Wei et al. (47).

The virtual RFLP pattern types revealed that one of the three 16SrII PPT phytoplasma strains identified in potato samples had a pattern type identical to faba bean phyllody phytoplasma (FBP); therefore, this phytoplasma strain (PPT-SINTV) is considered to be a new member of subgroup 16SrII-C. The remaining two strains (PPT-GTO29 and-GTO30) showed the same virtual RFLP patterns, but those were different at least in one band with previously described phytoplasma subgroups, and their similarity coefficient was equal to or less than 0.97 with each of the other known subgroups (Fig. 3 and Table 2); therefore, PPT-GTO29 and PPT-GTO30 phytoplasma strains were designated as new subgroup $\mathrm{M}$ (16SrI-M).

Following the criteria used for the $16 \mathrm{SrI}$ and 16SrII phytoplasma groups, the phytoplasma strains (PPT-COAHP and PPTGTOP) belonging to the X-disease group (16Sr-III) showed the same virtual RFLP patterns, but those were different at least in one band from previously described phytoplasma subgroups, and their similarity coefficients were equal to or less than 0.97 with each of the other known subgroups (Fig. 3 and Table 2); hence, we designated PPT-COAHP and PPT-GTOP phytoplasma strains as new subgroup S (16SrIII-S). The only phytoplasma strain (PPT-SINPV) belonging to the Mexican periwinkle virescence group (16SrXIII) showed a different virtual RFLP pattern from the other known subgroups (Fig. 3 and Table 2); therefore, we designated PPT-SINPV phytoplasma strains as new subgroup D (16SrXIII-D).

The actual gel-based PCR-RFLP analysis was done on likely new potato phytoplasma strains and PeLL and ToLL phytoplasma reference strains to verify the results of the virtual analysis (data not shown).

The actual gel-based RFLP analysis generated restriction profiles identical to those produced by virtual RFLP analysis (data not shown). The virtual different RFLP profiles that delineated new subgroups in the 16SrI, 16SrII, 16SrIII, and 16SrXIII phytoplasma groups are shown in Figure 4. PPT-JAL6 phytoplasma strain subgroup U (16SrI-U) can be differentiated from PeLL and/or ToLL phytoplasma strain subgroups $\mathrm{S}$ and $\mathrm{T}$ (16SrI-S and $16 \mathrm{SrI}-\mathrm{T}$, respectively) by the restriction enzyme MseI, while PPT-SON18 phytoplasma strain subgroup V (16SrI-V subgroup) can be differentiated from PeLL and/or ToLL phytoplasma strains by the restriction enzyme HinfI. The PPT-GTO29 and PPT-GTO30 phytoplasma strains sub- group M (16SrII-M) can be differentiated from faba bean phyllody phytoplasma strain subgroup $\mathrm{C}$ (16SrII-C) by the restriction enzyme Bst UI. The PPT-COAHP or PPT-GTOP phytoplasma strains subgroup $S$ (16SrIII-S) can be differentiated from milkweed yellows phytoplasma strain subgroup F (16SrIII-F) by the restriction enzymes BstUI, HinfI, and RsaI. The PPTSINPV phytoplasma strain subgroup D (16SrIII-D) can be differentiated from Mexican periwinkle virescence subgroup A (16SrXIII-A) by the restriction enzymes AluI, HpaII, and RsaI.

Phylogenetic analysis. The $16 \mathrm{~S}$ rDNA sequences of the above 17 phytoplasma strains associated with PPT were compared with 19 ' $\mathrm{Ca}$. Phytoplasma' species, other phytoplasmas representing distinct phytoplasma groups or subgroups, and $A$. palmae yielding the consensus tree illustrated in Figure 2. This tree shows that 11 PPT phytoplasma strains (PPT-BC1, PPTBC8, PPT-BC15, PPT-COAH10, PPTCOAH19, PPT-GTO5, PPT-JAL2, PPTJAL6, PPT-SIN6, PPT-SIN15, and PPTSON18) were clustered with ' $\mathrm{Ca}$. P. asteris', three PPT phytoplasma strains (PPTGTO29, PPT-GTO30, and PPT-SINTV) were clustered with ' $\mathrm{Ca}$. P. aurantifolia', two PPT phytoplasma strains (PPTCOAHP and PPT-GTOP) were clustered into the 16SrIII group (X-disease group), and one PPT phytoplasma strain (PPTSINPV) was clustered into the 16SrXIII group (Mexican periwinkle virescence group).

\section{DISCUSSION}

PPT disease has caused severe economic losses in various Mexican states and in North America. Prior to the present study, at least eight distinct phytoplasma strains belonging to five different phytoplasma groups (16SrI, 16SrII, 16SrIII, 16SrVI, and 16SrXVIII) have been associated with PPT disease in different regions of North America and Mexico. The PPT disease was previously associated with two different phytoplasma strains belonging to the 16SrI and 16SrII groups in Mexico (29). We have found that other PPT phytoplasma strains belonging to the $16 \mathrm{SrIII}$ and 16SrXIII groups are also associated with PPT disease in Mexico. At least three PPT phytoplasma strains were found in potato growing areas (COAH and GTO) where high incidence of the disease has been reported (34).

The aster yellows group was the most widespread in potato growing areas in Mexico. These results are not surprising because the aster yellows phytoplasma (16SrI, ' $C a$. P. asteris') represents the most diverse and widespread phytoplasma group. Subgroups 16SrI-A, I-B, and I-C are distributed worldwide and are associated with more than 80 plant species. Subgroups 16SrI-F, I-L, I-M, and I-P appear to be restricted to the European continent. 
The subgroup 16SrI-D is only found in Asia (4,27). Subgroup 16SrI-B represents the largest and most diverse strain cluster in the group (27). In Mexico, a PPT phytoplasma strain associated with PPT disease had been considered as a new member of aster yellows group, and two little leaf phytoplasma strains (PeLL and ToLL) associated with pepper and tomato diseases have also been considered as new subgroups of aster yellows group (16SrI-S and $16 \mathrm{SrI}-\mathrm{T}$, respectively) $(29,39)$. Phytoplasma strains belonging to subgroup 16SrI-A have been associated with PPT disease in Texas and Nebraska, USA (23) and 16SrI-B in Santa Cruz Province, Bolivia (18).

The peanut witches'-broom group (16SrII-C and 16SrII-M) was found in the GTO and SIN areas. This group is distributed worldwide, being reported in areas of Southeast Asia, Southern Europe, Africa, New Zealand, Australia, and America $(4,45)$. Another PPT phytoplasma strain belonging to peanut witches'-broom group associated with PPT disease was found in Mexico, and it was one of the first phytoplasma strains reported on the American continent. This phytoplasma strain was also found infecting cacti growing as weeds surrounding potato crops (29).

The $\mathrm{X}$-disease group was found in the $\mathrm{COAH}$ and GTO areas. This group has been reported on various plant species in areas of North and South America, and constitutes one of the most ubiquitous phytoplasma groups worldwide. Subgroups 16 SrIII-A and 16SrIII-F are found only in North America; 16SrIII-B in America, Asia, and Europe; 16SrIII-C, -D, -E, $-\mathrm{G},-\mathrm{I}$, and $-\mathrm{Q}$ in the United States; 16SrIII$\mathrm{H}$ is distributed worldwide; and 16SrIIIP

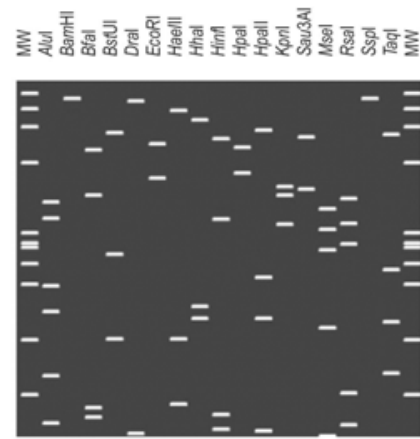

16SrI-S Pepper little leaf

Phytoplasma

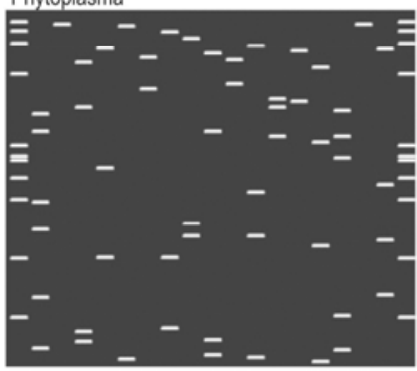

16SII-U PPT-JAL6

Phytoplasma

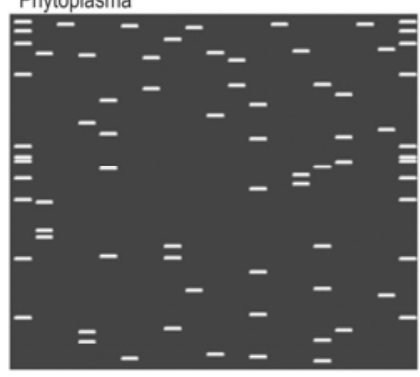

16Srll-M PPT-GTO29, -GTO30

Phytoplasma

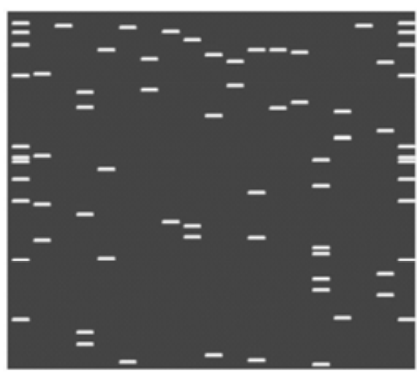

16SזXIII-D PPT-SINPV

Phytoplasma

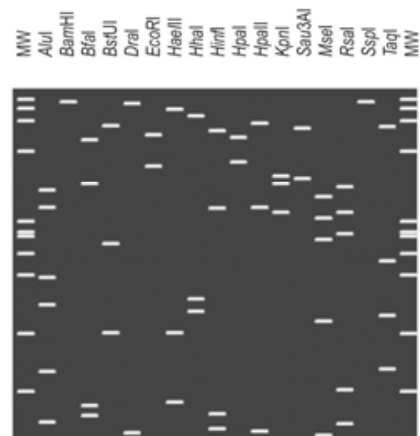

16SrI-T Tomato little leaf

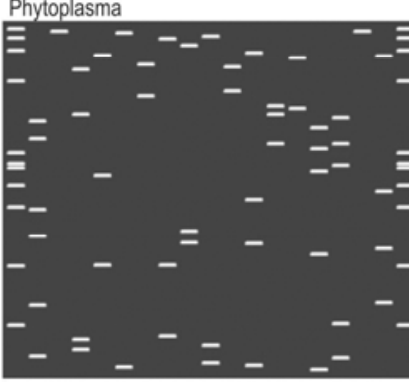

16Srl-V PPT-SON18

Phytoplasma

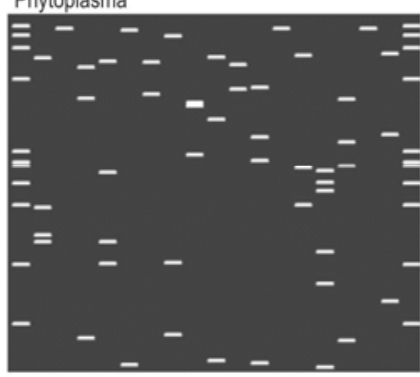

16Srlll-F Milkweed yellows

Phytoplasma

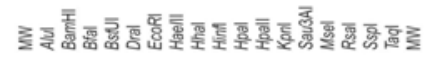

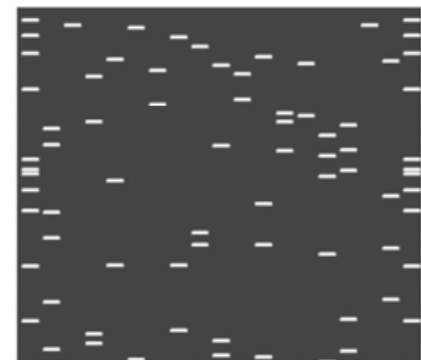

16SrI-S PPT-BC1, -BC8, -BC15, -COA10, -GTO5, -JAL2, -SIN6, -SIN15 Phytoplasma

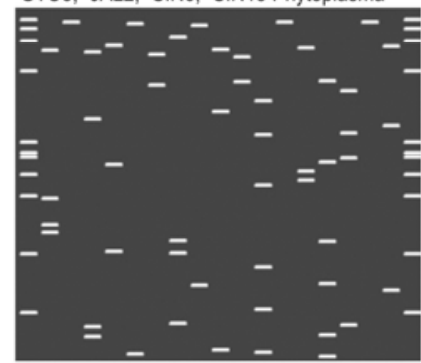

16Srll-C Faba Bean Phyllody Phytoplasma

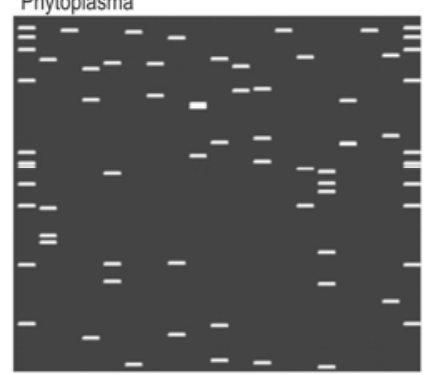

16SrIll-S PPT-COAHP, -GTOP

Phytoplasma

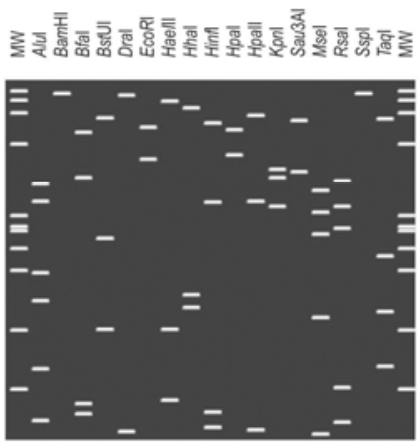

16SII-T PPT-COAH19

Phytoplasma

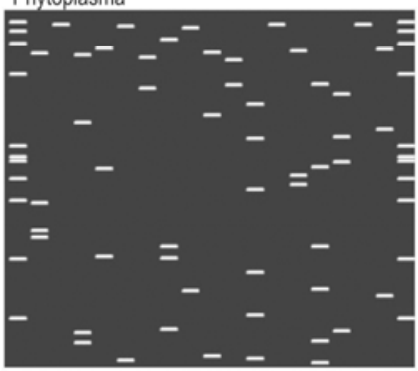

16SrIl-C PPT-SINTV

Phytoplasma

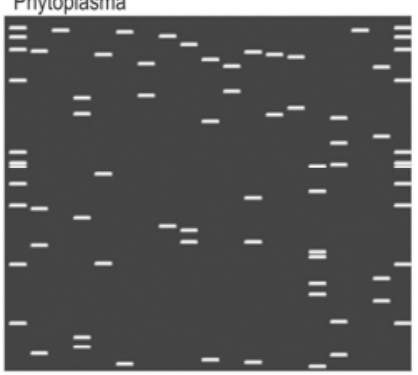

16SrXIII-A Mexican periwinkle

Virescence Phytoplasma

Fig. 3. Distinct virtual restriction fragment length polymorphism (RFLP) patterns derived from in silico digestions of 16S rRNA gene F2nR2 fragments from strains of new and previously delineated 16SrI, -II, -III, and -XIII subgroups. Recognition sites for the following 17 restriction enzymes were used in the simulated digestions: AluI, BamHI, BfaI, BstUI, DraI, EcoRI, HaeIII, HhaI, HinfI, HpaI, HpaII, KpnI, Sau3AI, MseI, RsaI, SspI, and TaqI. MW = molecular weight standards from a $\varphi$ X174 DNA-HaeIII digest. 
and 16 SrIII-R are found in Europe $(4,8,17)$. Recently, a phytoplasma strain belonging to subgroup 16SrIII-M has been associated with PPT disease in Montana, USA (24). This phytoplasma strain is very similar or identical to phytoplasmas found in COAH and GTO.

The Mexican periwinkle virescence group was only found in the SIN area. This group appears to be restricted to the American continent. Subgroup 16SrXIII-A was detected for the first time in periwinkle samples from Mexico (10), subgroup 16 SrXIII-B was detected in strawberry samples in Florida $(15,16)$, and subgroup 16SrXIII-C was detected in chinaberry trees in Bolivia and Argentina $(2,13)$. A phytoplasma strain belonging to Mexican periwinkle virescence group (16SrXIII-A) was previously reported in the Baja California peninsula of Mexico associated with a yellows type disease affecting tomato plants (14).

Arneodo et al. (2) determined the diversity and geographical distribution of phytoplasmas infecting china-tree in Argentina. They found that two different phytoplasmas belonging to groups $16 \mathrm{SrIII}$ and $16 \mathrm{SrXIII}$ were infecting china-tree. In addition, the RFLP analysis of these phytoplasma groups of different geographic origin did not reveal any intra-group variation. On the other hand, another study based on virtual RFLP analysis and calculated coefficients of RFLP pattern similarities revealed a remarkable genetic diversity among cactus witches'-broom (CaWB) phytoplasma strains infecting Opuntia species in China (5). Our results from 16S rDNA sequence and virtual RFLP analyses of PPT phytoplasma strains from different geographic origins revealed inter- and intra-group variation. These results showed the occurrence of four different phytoplasma groups infecting potato crops in Mexico (groups 16SrI, 16SrII, 16SrIII, and 16SrXIII). Eight PPT phytoplasma strains (PPT-BC1, PPT-BC8, PPT-BC15, PPTCOAH10, PPT-GTO5, PPT-JAL2, PPTSIN6, and PPT-SIN15) were considered to be new members of subgroup 16SrI-S; one strain (PPT-COAH19) was considered to be a new member of subgroup 16SrI-T; two strains (PPT-JAL6 and PPT-SON18) were designated as new subgroups $U$ and $\mathrm{V}$ (16SrI-U and 16SrI-V, respectively) of aster yellows group; one strain (PPTSINTV) was considered to be a new member of subgroup 16SrII-C; two strains (PPT-GTO29 and PPT-GTO30) were designated as new subgroup M (16SrII-M) of the peanut witches'-broom group; two strains (PPT-COAHP and PPT-GTOP) were designated as new subgroup $\mathrm{S}$ (16SrIII-S) of X-disease group; one strain (PPT-SINPV) was designated as new subgroup D (16SrXIII-D) of the Mexican periwinkle virescence group.

Symptoms of plants infected by PPT resemble those of psyllid yellows (PY) and zebra chip (ZC); $\mathrm{ZC}$ is a new potato disease that was first observed in Texas, USA and Saltillo, Mexico in 1994 (35,41). Our results show that only $15.1 \%$ of foliage

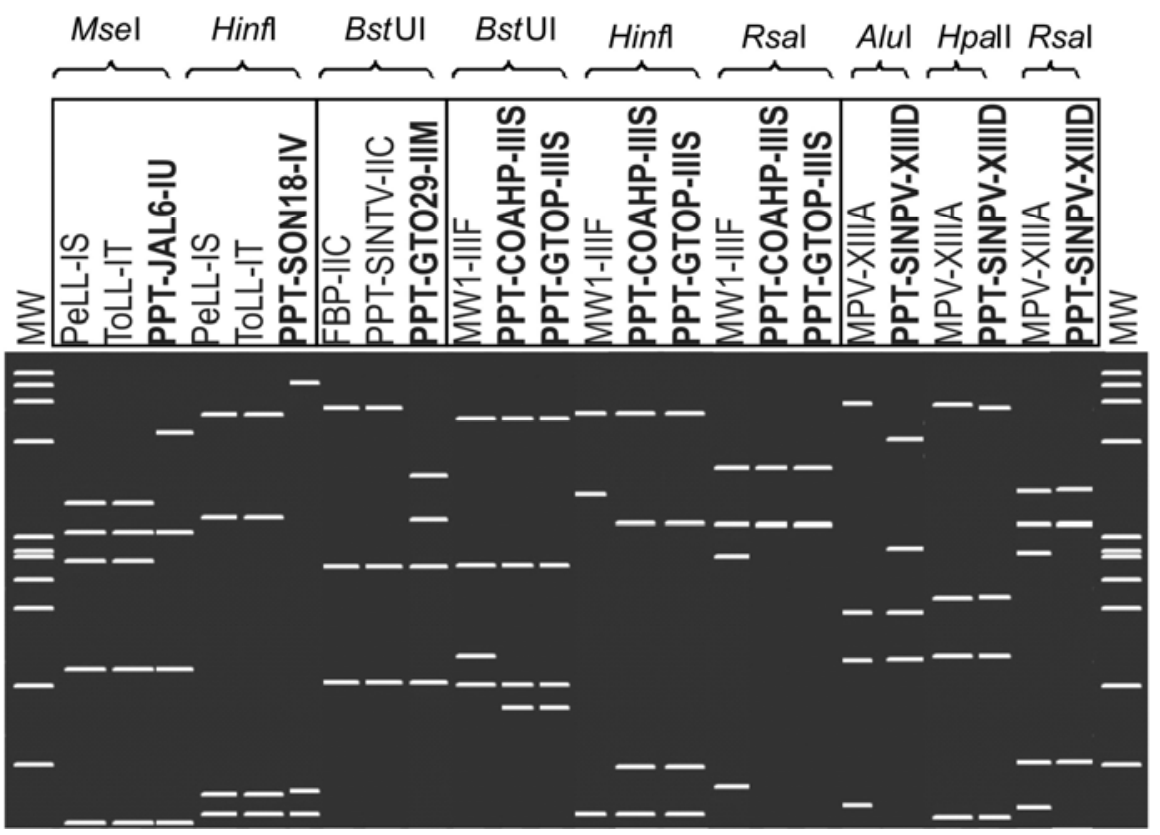

Fig. 4. Key restriction enzymes that distinguish the new phytoplasma subgroups (AluI, BstUI, HinfI, HpaII, MseI, and RsaI). Restriction patterns were obtained by virtual restriction fragment length polymorphism (RFLP) analysis of 16S rDNA sequences of strains from the new 16SrI, 16SrII, 16SrII, and 16SrXIII subgroups and sequence from a known member of each subgroup was used as a reference (GenBank accession numbers: PeLL-IS, DQ092321; ToLL-IT, DQ375238; PPT-JAL6-IU, FJ914650; PPT-SON18-IV, FJ914642; FBP-IIC, X83432; PPT-SINTV-IIC, FJ914651; PPT-GTO29IIM, FJ914643; MW1-IIIF, AF510724; PPT-COAHP-IIIS, FJ914645; PPT-GTOP-IIIS, FJ914646; MPV-XIIIA, AF248960; PPT-SINPV-XIIID, FJ914647). MW, $\varphi$ X174 DNA-HaeIII digest. New phytoplasma subgroups are in bold.

samples from symptomatic and nonsymptomatic plants collected in representative fields of all potato growing areas in Mexico were PCR-positive for phytoplasmas. Hence, our results may suggest that one or more other pathogens may be involved in PPT disease in Mexico. In January 2008, a Liberibacter species designated as 'Candidatus Liberibacter solanacearum' (33) was associated with diseases of tomato and pepper plants and other members of the family Solanaceae in New Zealand $(30,31)$. In Mexico and the United States, the new Liberibacter species was associated, on September and June 2008, with potato $\mathrm{ZC}$ in Saltillo and Texas, respectively (1,36). In March 2009, 'Ca. L. solanacearum' was also detected in tomato and bell pepper plants in Sinaloa, Mexico $(37,38)$. In January 2009, 'Candidatus Phytoplasma australiense' was found in mixed infection with ' $\mathrm{Ca}$. L. solanacearum' in New Zealand (32). Phytoplasma strains of different groups (16SrI, 16SrII, and $16 \mathrm{SrXIII)}$ have been detected in the psyllid Bactericera cockerelli collected from potato and pepper plants in Mexico, and these phytoplasmas were transmitted by this psyllid to potato, pepper, and tomato plants (6). ' $\mathrm{Ca}$. L. solanacearum' was also detected in $B$. cockerelli collected from tomato plants in Texas (11), and this psyllid was able to transmit ZC and PY to tomato and potato plants $(11,42)$. Therefore, $B$. cockerelli seems to be involved in a new psyllid disease complex caused by different phytoplasma strains and possibly ' $C a$. L. solanacearum'. More studies are needed to establish the incidence and impact of phytoplasmas and ' $\mathrm{Ca}$. L. solanacearum' in Mexico.

\section{ACKNOWLEDGMENTS}

We thank CONACYT, project SAGARPA-2002609, Fundación Produce Sinaloa, Consejo Estatal de Ciencia y Tecnología del Estado de Sinaloa, and Instituto Politécnico Nacional for the economic support of this research project. We also thank Celestino Vargas Ramírez for his technical support with the Perl program and Ana Lucia Alvarado García for the editing of figures.

\section{LITERATURE CITED}

1. Abad, J. A., Bandla, M., French-Monar, R. D., Liefting, L. W., and Clover, G. R. G. 2009 First report of the detection of 'Candidatus Liberibacter' species in zebra chip diseaseinfected potato plants in the United States. Plant Dis. 93:108.

2. Arneodo, J. D., Marini, D. C., Galdeano, E. Meneguzzi, N., Bacci, M., Domecq, C., Nome S. F., and Conci, L. R. 2007. Diversity and geographical distribution of phytoplasmas infecting china-tree in Argentina. J. Phytopathol. 155:70-75.

3. Banttari, E. E., Orr, P. H., and Preston, D. A 1990. Purple top wilt of potatoes caused by the aster yellows virus. Trans. ASAE 33:221-226.

4. Bertaccini, A. 2007. Phytoplasmas: Diversity, taxonomy, and epidemiology. Front. Biosci. 12:673-689

5. Cai, H., Wei, W., Davis, R. E., Chen, H., and Zhao, Y. 2008. Genetic diversity among phytoplasmas infecting Opuntia species: Virtual RFLP analysis identifies new subgroups in the 
peanut witches'-broom group. J. Syst. Evol. Microbiol. 58:1448-1457.

6. García-Negroe, C. B. 2007. Tesis de Maestría. Centro de Investigación Interdisciplinario para el Desarrollo Integral Regional, Unidad Sinaloa. Instituto Politécnico Nacional. Guasave, Sinaloa, México.

7. Girsova, N., Bottner, K. D., Mozhaeva, K. A., Kastalyeva, T. B., Owens, R. A., and Lee, I.M. 2008. Molecular detection and identification of group $16 \mathrm{SrI}$ and $16 \mathrm{SrXII}$ phytoplasmas associated with diseased potatoes in Russia. Plant Dis. 92:654.

8. Griffiths, H. M., Gundersen, D. E., Sinclair, W. A., Lee, I. M., and Davis, R. E. 1994. Mycoplasmalike organisms from milkweed, goldenrod, and spirea represent two new 16S rRNA subgroups and three new strain subclusters related to peach X-disease. Can. J. Plant Pathol. 16:255-266.

9. Gundersen, D. E., and Lee, I. M. 1996. Ultrasensitive detection of phytoplasmas by nestedPCR assay using two universal primer pairs. Phytopathol. Mediterr. 35:144-151.

10. Gundersen, D. E., Lee, I.-M., and Davis, R. E. 1994. RFLP analyses of ribosomal protein genes reveal strain diversity in MLO $16 \mathrm{~S}$ rRNA groups I and III. (Abstr.) Phytopathology $84: 1128$.

11. Hansen, A. K., Trumble, J. T., Stouhamer, R., and Paine, T. D. 2008. A new huanglongbing species, 'Candidatus Liberibacter psyllaurous', found to infect tomato and potato, is vectored by the psyllid Bactericera cockerelli (Sulc). Appl. Environ. Microbiol. 74:5862-5865.

12. Harding, R. M., and Teakle, D. S. 1985. Mycoplasma-like organisms as causal agents of potato purple top in Queensland. Aust. J. Agric. Res. 36:443-449.

13. Harrison, N. A., Boa, E., and Carpio, M. L. 2003. Characterization of phytoplasmas detected in chinaberry trees with symptoms of leaf yellowing and decline in Bolivia. Plant Pathol. 52:147-157.

14. Holguín-Peña, R. J., Vázquez-Juárez, R. C., and Martínez-Soriano, J. P. 2007. First report of a $16 \mathrm{SrI}-\mathrm{B}$ group phytoplasma associated with a yellows-type disease affecting tomato plants in the Baja California Peninsula of Mexico. Plant Dis. 91:328.

15. Jomantiene, R., Davis, R. E., Maas, J., and Dally, E. L. 1996. Phytoplasmas associated with disease of strawberry in Florida. (Abstr.) Phytopathology 86:S123.

16. Jomantiene, R., Davis, R. E., Maas, J., and Dally, E. L. 1998. Classification of new phytoplasmas associated with diseases of strawberry in Florida based on analysis of 16S rRNA and ribosomal protein gene operon sequences. Intern. J. Syst. Bacteriol. 48:269-277.

17. Jomantiene, R., Davis, R. E., Valiunas, D., and Alminaite, A. 2002. New group 16SrIII phytoplasma lineages in Lithuania exhibiting rRNA interoperon sequence heterogeneity. Eur. J. Plant Pathol. 108:507-517.

18. Jones, P., Arocha, Y., Antesana, O., Montellano, E., and Franco, P. 2005. "Brotes grandes" (big bud) of potato: A new disease associated with a 16SrI-B subgroup in Bolivia. Plant Pathol. 54:234

19. Jung, H. Y., Hahm, Y. I., Lee, J. T., Hibi, T., and Namba, S. 2003. Characterization of a phytoplasma associated with witches'-broom disease of potatoes in Korea. J. Gen. Plant Pathol. 69:87-89.

20. Khadhair, A. H., Hiruki, C., Hwang, S. F., and
Wang, K. 1997. Molecular identification and relatedness of potato witches'-broom phytoplasma isolates from four potato cultivars. Microbiol. Res. 152:281-286.

21. Khadhair, A. H., and McAllister, P. D. 2003. Transmission and characterization of phytoplasma diseases associated with infected potato cultivars in Alberta. Acta Hortic. 169:167176.

22. Lee, I.-M., Bottner, K. D., Munyaneza, J. E., Secor, G. A., and Gudmestad, N. C. 2004. Clover prolifertion group (16SrVI) subgroup A (16SrVI-A) phytoplasma is a probable causal agent of potato purple top disease in Washington and Oregon. Plant Dis. 88:429.

23. Lee, I. M., Bottner, K. D., Secor, G. A., and Rivera-Varas, V. 2006. 'Candidatus Phytoplasma americanum', a phytoplasma associated with a potato purple top wilt disease complex. Intern. J. Syst. Evol. Microbiol. 56:15931597.

24. Lee, I.-M., Bottner, K. D., and Sun, M. 2009. An emerging potato purple top disease associated with a new 16 SrIII group phytoplasma in Montana. Plant Dis. 93:970.

25. Lee, I. M., Davis, R. E., and Gundersen, D. E. 2000. Phytoplasma: Phytopathogenic mollicutes. Annu. Rev. Microbiol. 54:221-555.

26. Lee, I. M., Dawn, E., Gundersen, D. E., and Davis, R. E. 1998. Revised classification scheme of phytoplasmas based on RFLP analyses of $16 \mathrm{~S}$ rRNA and ribosomal protein gene sequences. Intern. J. Syst. Bacteriol. 48:1153-1169.

27. Lee, I. M., Gundersen, D. E., Davis, R. E., Bottner, K. D., Marcone, C., and Seemüller, E. 2004. 'Candidatus Phytoplasma asteris', a novel phytoplasma taxon associated with aster yellows and related diseases. Intern. J. Syst. Evol. Microbiol. 54:1037-1048.

28. Leyva-López, N. E., Aguilar-Rojas, O. I., LealKlevezas, D. S., and Martínez-Soriano, J. P. 1999. Presence of phytoplasmas in Mexican cacti. (Abstr.) Phytopathology 89:S45.

29. Leyva-López, N. E., Ochoa-Sánchez, J. C., Leal-Klevezas, D. S., and Martínez-Soriano, J. P. 2002. Multiple phytoplasmas associated with potato diseases in Mexico. Can. J. Microbiol. 48:1062-1068.

30. Liefting, L. W., Perez-Egusquiza, Z. C., Clover, G. R. G., and Anderson, J. A. D. 2008. A New 'Candidatus Liberibacter' species in Solanum tuberosum in New Zealand. Plant Dis. 92:1474.

31. Liefting, L. W., Sutherland, P. W., Ward, L. I., Paice, K. L., Weir, B. S., and Clover, G. R. G. 2009. A New 'Candidatus Liberibacter' species associated with diseases of solanaceous crops. Plant Dis. 93:208-214.

32. Liefting, L. W., Veerakone, S., Ward, L. I., and Clover, G. R. G. 2009. First report of 'Candidatus Phytoplasma australiense' in potato. Plant Dis. 93:969.

33. Liefting, L. W., Weir, B. S., Pennycook, S. R., and Clover, G. R. G. 2009. 'Candidatus Liberibacter solanacearum' associated with plants in the family Solanaceae. Intern. J. Syst. Evol. Microbiol. 59:2274-2276.

34. Martínez-Soriano, J. P., Leyva-López, N. E., Zavala-Soto, M. E., Berès, M., and LealKlevezas, D. S. 1999. Detección molecular del agente causal del síndrome "bola de hilo" de la papa en semillas infectadas y asintomáticas. Biotecnol. Apl. 16:93-96.

35. Munyaneza, J. E., Crosslin, J. M., and Upton, J. E. 2007. Association of Bactericera cock- erelli (Homoptera: Psyllidae) with "Zebra Chip", a new potato disease in Southwestern United States and Mexico. J. Econ. Entomol. 100:656-663.

36. Munyaneza, J. E., Sengoda, V. G., Crosslin, J. M., De la Rosa-Lozano, G., and Sanchez, A. 2009. First report of 'Candidatus Liberibacter psyllaurous' in potato tubers with Zebra Chip disease in Mexico. Plant Dis. 93:552.

37. Munyaneza, J. E., Sengoda, V. G., Crosslin, J. M., Garzón-Tiznado, J. A., and CardenasValenzuela, O. G. 2009. First report of "Candidatus Liberibacter solanacearum" in tomato plants in México. Plant Dis. 93:1076.

38. Munyaneza, J. E., Sengoda, V. G., Crosslin, J. M., Garzón-Tiznado, J. A., and CardenasValenzuela, O. G. 2009. First report of 'Candidatus Liberibacter solanacearum' in pepper plants in México. Plant Dis. 93:1076.

39. Santos-Cervantes, M. E., Chávez-Medina, J A., Méndez-Lozano, J., and Leyva-López, N. E. 2008. Detection and molecular characterization of two little leaf phytoplasma strains associated with pepper and tomato diseases in Guanajuato and Sinaloa, Mexico. Plant Dis. 92:1007-1011.

40. Secor, G. A., Lee, I.-M., Bottner, K. D. Rivera-Varas, V., and Gudmestad, N. C. 2006. First report of a defect of processing potatoes in Texas and Nebraska associated with a new phytoplasma. Plant Dis. 90:377.

41. Secor, G. A., and Rivera-Varas, V. 2004 Emerging diseases of cultivated potato and their impact on Latin America. Rev. Latinoamericana de la papa (suppl.) 1:1-8.

42. Secor, G. A., Rivera, V. V., Abad, J. A., Lee, I. M., Clover, G. R. G., Liefting, L. W., Li, X. and De Boer, S. H. 2009. Association of 'Candidatus Liberibacter solanacearum' with zebra chip disease of potato established by graft and psyllid transmission, electron microscopy, and PCR. Plant Dis. 93:574-583.

43. Secretaría de Agricultura, Ganadería, Desarrollo Rural, Pesca y Alimentación (SAGARPA). Servicio de Información Agroalimentaria y Pesquera (SIAP). 2008. Published online at: http://www.siap.gob.mx

44. Smart, C. D., Thomson, S. V., Flint, K., and Kirkpatrick, B. C. 1993. The beet leafhopper transmitted virescence agent is associated with diseased potatoes in Utah. (Abstr.) Phytopathology 83:1399.

45. Tolu, G., Botti, S., Garau, R., Prota, V. A. Sechi, A., Prota, U., and Bertaccini, A. 2006. Identification of a 16 SrII-E phytoplasma in Calendula arvensis, Solanum nigrum, and Chenopodium spp. Plant Dis. 90:325-330.

46. Wei, W., Davis, R. E., Lee, I. M., and Zhao, Y. 2007. Computer-simulated RFLP analysis of 16S rRNA genes: Identification of ten new phytoplasma groups. Intern. J. Syst. Evol. Microbiol. 57:1855-1867.

47. Wei, W., Lee, I. M., Davis, R. E., Suo, X., and Zhao, Y. 2008. Automated RFLP pattern comparison and similarity coefficient calculation for rapid delineation of new and distinct phytoplasma $16 \mathrm{Sr}$ subgroup lineages. Intern. J. Syst. Evol. Microbiol. 58:2368-2377.

48. Younkin, S. G. 1943. Purple top wilt of potatoes caused by the aster yellows virus. Am. Potato J. 20:177-183.

49. Zhang, Y. P., Uyemoto, J. K., and Kirkpatrick, B. C. 1998. A small-scale procedure for extracting nucleic acids from woody plants infected with various phytopathogens for PCR assay. J. Virol. Methods 71:45-50. 